
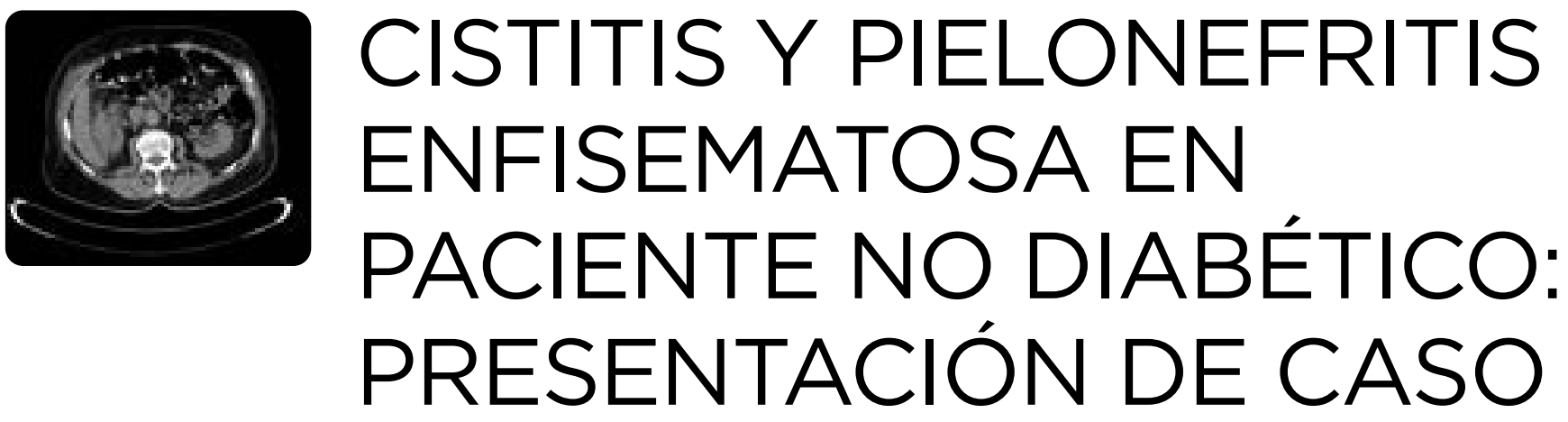

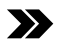

\section{Palabras clave (DeCS)}

Cistitis

Pielonefritis

Adulto

\section{Key words (MeSH)}

Cystitis

Pyelonephritis

Adult
'Radiólogo, Departamento de Imágenes Diagnósticas Fundación Cardioinfantil. Bogotá, Colombia.

${ }^{2}$ Estudiante de Medicina, Universidad Colegio Mayor Nuestra Señora del Rosario. Bogotá, Colombia.

3Médica general, Universidad El Bosque. Bogotá, Colombia.

\title{
Cystitis and Emphysematous Pyelonephritis In
} Non-Diabetic Patient: Case Report

Gabriel Caviedes Jenny Barbosa Tavera² Andrés Felipe Pineda Martínez ${ }^{2}$ María José Veloza Vega ${ }^{3}$

\section{Resumen}

La cistitis y la pielonefritis enfisematosa (PNE) son las infecciones del tracto urinario más frecuentes en mujeres, un 90 \%, con factores de riesgo como diabetes y obstrucción. Son provocadas por la colonización de patógenos gramnegativos (E. Coli, Klebsiella), los cuales producen gas lo que genera un patrón clínico e imagenológico característico. Se presenta un caso en el que el paciente diagnosticado con pielonefritis enfisematosa no cuenta con las características habituales ni con los factores de riesgo frecuentes de esta entidad. Se destaca que un análisis correcto de las imágenes radiológicas y una evaluación clínica adecuada son fundamentales para su diagnóstico y apropiado tratamiento.

\section{Summary}

Cystitis and emphysematous pyelonephritis (EPN) are the most common urinary tract infections in women, 90\%, with risk factors such as diabetes and obstruction. They are caused by the colonization of gram-negative pathogens (E. Coli, Klebsiella), which are capable of producing gas and cause the corresponding clinical and imaging pattern. We present a case in which the patient diagnosed with emphysematous pyelonephritis does not have the usual characteristics or frequent risk factors of this entity. It is emphasized that a correct analysis of the radiological images and an adequate clinical evaluation are fundamental for its diagnosis and appropriate treatment.

\section{Introducción}

La cistitis enfisematosa (CE) y la pielonefritis enfisematosa (PNE) son entidades poco frecuentes que se caracterizan por la presencia de gas en el tracto urinario; sin embargo, en la primera de estas el gas se encuentra en la pared de la vejiga y, ocasionalmente, dentro de ella (1), mientras que en la segunda, la cual es una infección difusa, supurativa, necrosante y potencialmente mortal, causada por uropatógenos gramnegativos (2), el gas se localiza en el parénquima renal, el sistema colector o el tejido perinefrítico (3).
En este artículo se expone el caso de un hombre de 83 años de edad, quien además de sufrir las dos patologías de forma concomitante, diagnosticadas mediante el uso de imágenes radiológicas, tuvo sepsis como complicación de las mismas.

\section{Presentación del caso}

Se trata de un paciente masculino de 83 años de edad, con antecedentes de hipertensión arterial, falla cardiaca, fibrilación auricular, hiperplasia prostática benigna (HPB) 


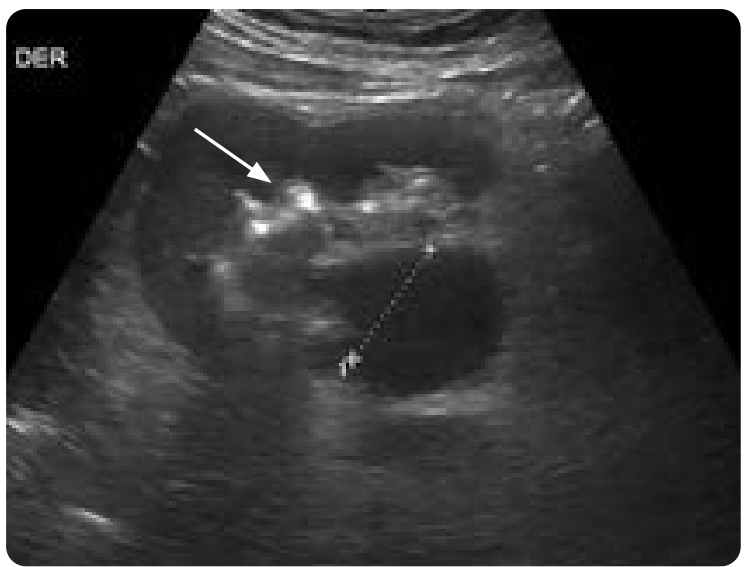

Figura 1. Ecografía de vías urinarias, modo B. Riñón derecho, plano transversal: Dilatación pielocalicial del riñón derecho con diámetro anteroposterior de la pelvis renal de $26 \mathrm{~mm}$. Imágenes ecogénicas sin sombra acústica sugestivas de gas (flecha).

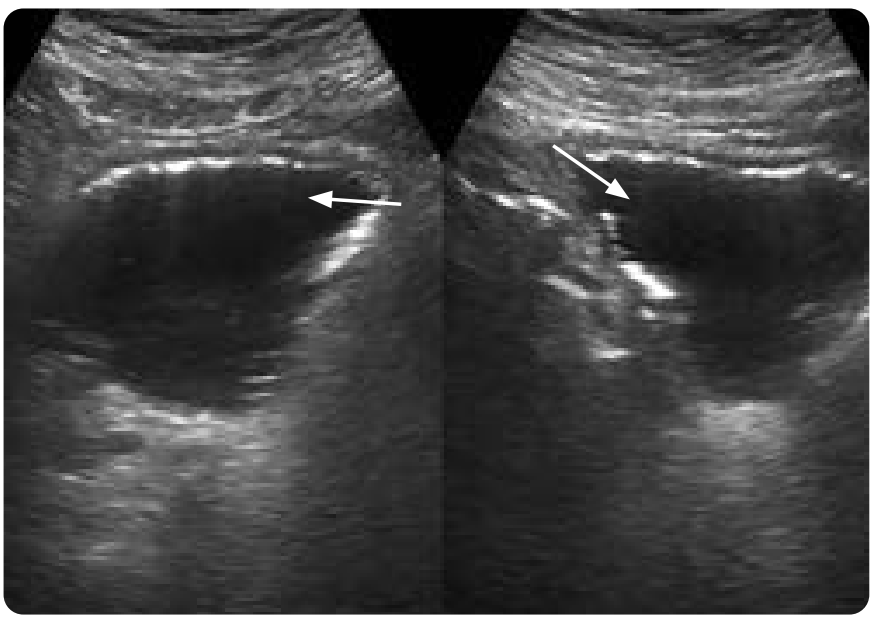

Figura 2. Ecografía de vías urinarias, modo B. a) Plano sagital. b) Plano transverso: Vejiga con imágenes ecogénicas en pared, sin sombra acústica posterior (flechas)

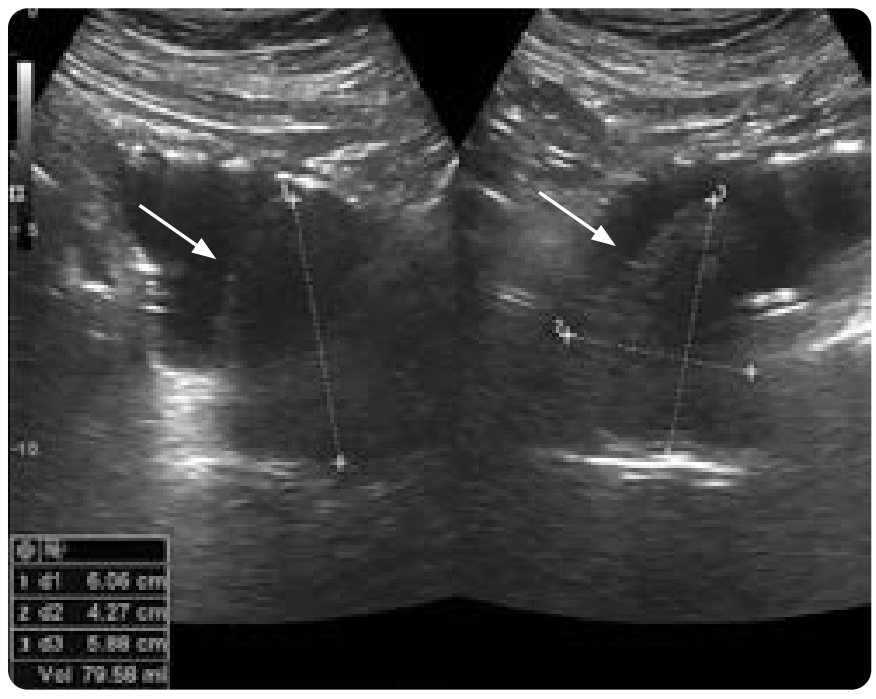

Figura 3. Ecografía de vías urinarias, modo B. a) Plano sagital. b) Plano transverso: Hiperplasia prostática con un volumen de $79 \mathrm{~cm} 3$ (flechas).
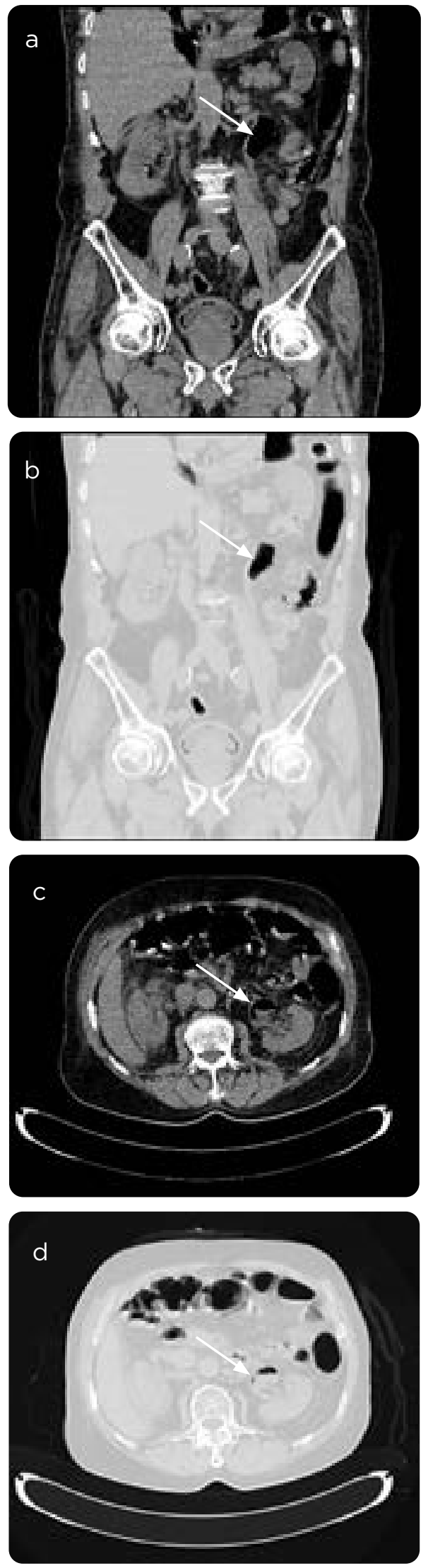

Figura 4. UROTAC. a) Cortes coronales en ventana de tejidos blandos y de pulmón. b) Cortes axiales en ventana de tejidos blandos y de pulmón: Pelvis extrarrenal izquierda, dilatada, con gas en su interior (flechas). 

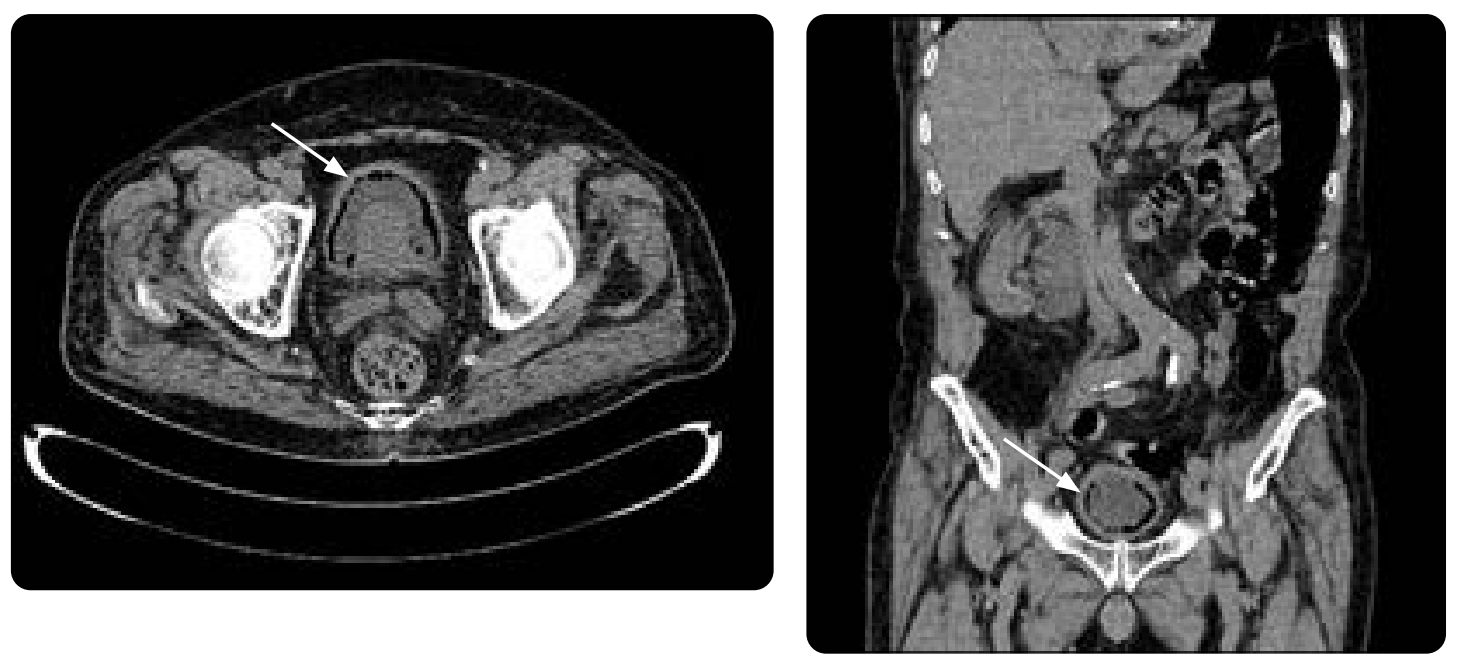

Figura 5. UROTAC. a) Corte axial. b) Corte coronal: Vejiga poco distendida, de paredes engrosadas, con aire en su interior (flechas).

en manejo con alfabloqueador, bicitopenia (leucopenia, trombocitopenia) y alcoholismo crónico. Consultó por cuadro clínico de tres días de evolución consistente en disuria, tenesmo vesical y hematuria, asociado a fiebre e hiporexia. Al examen físico se encontró hipotenso, sin otros hallazgos relevantes.

En la exploración con ecografía de vías urinarias se identificó dilatación pielocalicial del riñón derecho con diámetro anteroposterior de la pelvis renal de $26 \mathrm{~mm}$ (figura 1), imágenes ecogénicas sin sombra acústica posterior en los grupos caliciales, sugestivas de gas, y vejiga con imágenes ecogénicas de similares características (figura 2). Adicionalmente, se encontró hiperplasia prostática con un volumen de $79 \mathrm{~cm}^{3}$ (figura 3). Bajo la sospecha diagnóstica de cistitis enfisematosa se le practicó una tomografía de vías urinarias (UROTAC), la cual, además de confirmar este diagnóstico, determinó pielonefritis enfisematosa bilateral Huang 4, dados los hallazgos de pelvis extrarrenales dilatadas con niveles hidroaéreos (figura 4) y vejiga de paredes engrosadas con aire en su interior (figura 5).

Adicionalmente, en los demás paraclínicos se documentó hiperlactatemia y mediante hemocultivos se aislaron bacilos gramnegativos tipificados en urocultivo como Escherichia coli (E. coli). Se determinó una sepsis de origen urinario como diagnóstico adicional, la cual fue tratada mediante esquema antibiótico parenteral y derivación con sonda vesical.

\section{Discusión}

Tanto la CE como la PNE tienen como factores de riesgo clásicos: sexo femenino (75\%), diabetes mellitus (DM), edad avanzada con media de 55 años (2), inmunosupresión, estasis urinaria, inserción de catéteres urinarios o anomalía anatómica (1). Más de la mitad de los casos de CE y el $90 \%$ de PNE se asocian a DM $(2,4)$, la cual genera un aumento en la eliminación de la glucosa y con ello facilita su metabolismo por parte de bacterias gramnegativas aerobias, lo que facilita la producción de gases como $\mathrm{CO}_{2}(3,4)$. En pacientes sin DM se postula que los microorganismos utilizan el lactato urinario y proteínas para producir el gas (4). No obstante, en el caso descrito, aunque el paciente no padece DM, sí es de edad avanzada, con probable componente obstructivo en relación con HPB e inmunosupresión por antecedente de alcoholismo, lo cual aumenta el riesgo de infecciones potencialmente letales (5).
En cuanto a la manifestación clínica de las dos entidades, se observa sintomatología similar a la de una infección urinaria con disuria, hematuria y fiebre. Sin embargo, esta es muy variable, abarca desde pacientes completamente asintomáticos hasta casos potencialmente letales, sin que exista correlación entre el grado de inflamación y el estado clínico del paciente (3).

Aunque existe una alta sospecha diagnóstica por el cuadro clínico, los factores de riesgo y el hallazgo de imágenes ecogénicas focales en la ultrasonografía (US), el diagnóstico certero se lleva a cabo mediante tomografía computarizada (TC), la cual, en primer lugar detecta el proceso enfisematoso y determina su extensión, posibles causas y complicaciones $(1,4)$; en segundo lugar, disminuye los sesgos en la interpretación de la US que tiene una baja sensibilidad debido a la visualización limitada por el gas intestinal; $y$, en tercer lugar, permite evaluar la cantidad de parénquima renal afectado y clasificar la PNE, tal como se refirió en el caso donde la clase Huang-4 corresponde a enfisema renal bilateral. De esta forma, se evidencia que la TC es un método útil para el diagnóstico, planificación del tratamiento y determinación del pronóstico $(2,4,6,7)$.

En lo que respecta al tratamiento de la CE, este consiste en drenaje vesical para reducir la presión intravesical y antibioticoterapia parenteral de amplio espectro ajustada según antibiograma (1). Sin embargo, a pesar de que en el paciente se instauró precozmente este tratamiento, tuvo complicaciones de PNE y sepsis, por lo que requirió, según la literatura, terapias más agresivas, como drenaje percutáneo o nefrectomía para disminuir la morbimortalidad asociada, ya que en los casos de PNE tratados medicamente alcanza el $80 \%$ (2). No obstante, las decisiones terapéuticas deben estar fundamentadas en el estado clínico. En el caso en estudio, el cuadro clínico se resolvió con el manejo terapéutico conservador.

\section{Conclusión}

La cistitis y la pielonefritis enfisematosa son entidades poco frecuentes. Su diagnóstico es difícil, pues no se puede establecer mediante criterios clínicos ni imágenes radiológicas básicas y tienen una gravedad significativa ya que pueden ocasionar complicaciones potencialmente letales, como el choque séptico. Es imprescindible tener una alta sospecha en pacientes con factores de riesgo o que no 
respondan al tratamiento médico habitual, para realizar estudios de imagen que confirmen el diagnóstico, con el objetivo de instaurar precozmente el tratamiento médico o quirúrgico. Se puede concluir que la tomografía computarizada y la adecuada interpretación radiológica son fundamentales en el diagnóstico de estas patologías.

\section{Referencias}

1. Vera AN, Zwanzger MC, Troncoso CP. Emphysematous cystitis: Report of one case. Rev Med Chil. 2015;143(3):387-90.

2. Motta-Ramírez G, González-Merino L, Castillo-Lima J, Flores-Terrazas E, Bustamante-Romero F, Ríos-Mondragón L. Pielonefritis enfisematosa. Estudios radiológicos y de imagen Ultrasonido (US)-Tomografía Computada (TC) para su diagnóstico y manejo. Acta Médica Grupo Ángeles [Internet]. 2014 [citado 2019 feb.16];12(1). Disponible en: https://www.medigraphic.com/pdfs/actmed/am-2014/am141a.pdf.

3. Behera V, Vasantha Kumar RS, Mendonca S, Prabhat P, Naithani N, Nair V. Emphysematous infections of the kidney and urinary tract: a single-center experience. Saudi J Kidney Dis Transpl. 2014;25(4):823-9.

4. Irusta H, Ocantos J, Ulla M, Frank L, García Mónaco R. Cistitis enfisematosa en varón no diabético. Revista Argentina de Radiología. 2015;79(3):150-4.

5. Jacob A, Alagusundaramoorthy SS, Verma I, Bodala D. Unusual association of emphysematous cystitis and chronic alcoholism. BMJ Case Rep. 2017;2017.

6. Li S, Wang J, Hu J, He L, Wang C. Emphysematous pyelonephritis and cystitis: A case report and literature review. J Int Med Res. 2018;46(7):2954-60.

7. Islam M, Bancil AS, Ingram O. Emphysematous cystitis: a radiographic diagnosis. MJ Case Rep. 2016; 2016.

\section{Correspondencia}

María José Veloza Vega

Servicio de Imágenes Diagnósticas.

Fundación Cardioinfantil

Calle163A \# 13B-60, piso 1

Bogotá, Colombia

velozamariajose@gmail.com

Recibido para evaluación: 15 de mayo de 2019

Aceptado para publicación: 8 de agosto de 2019 